\title{
ERA UMA VEZ UMA PRINCESA E UM PRÍNCIPE...: REPRESENTAÇÕES DE GÊNERO NAS NARRATIVAS DE CRIANÇAS
}

\author{
Constantina Xavier Filha \\ Universidade Federal de Mato Grosso do Sul
}

\begin{abstract}
Resumo: As representações de gênero sobre o universo dos contos de fadas foram apreendidas em momentos de pesquisa-ação com crianças em uma escola pública em Campo Grande, capital do Mato Grosso do Sul. A pesquisa faz parte de estudo mais amplo, com apoio do CNPq, que apresenta dois eixos teórico-metodológicos: a pesquisa bibliográfica com a coleta, a seleção e a análise de livros infantis com as temáticas da sexualidade, gênero e diversidades: e a pesquisa-ação com crianças e adolescentes. Nesta segunda perspectiva, priorizaram-se discussões a partir de produção textual (escrita e ilustrativa) aliada à leitura e à discussão de livros para a infância coletados no primeiro eixo da investigação. No presente texto, apresento alguns dados do segundo eixo. Nele, buscamos entender como as crianças constroem representações de gênero a partir da descrição física e comportamental de princesas e príncipes dos contos de fadas clássicos. Observamos que suas representações são ligadas ao que socialmente e em termos hegemônicos é considerado ideal de masculinidade e feminilidade. Algumas resistências são observadas na produção textual dos meninos. As meninas parecem mais conformadas aos ditames de gênero, considerados como a possibilidade ideal e desejável para a sua constituição identitária.
\end{abstract}

Palavras-chave: representações de gênero; pesquisa com crianças; gênero.

\section{Adentrando o mundo encantado de princesas e príncipes}

Era uma vez uma princesa que se casou com um príncipe e viveram felizes para sempre! Essa frase povoa o nosso imaginário. O príncipe e a princesa, como personagens de contos de fadas, são emblemáticos e trazem consigo elementos simbólicos e representativos de várias questões como o amor romântico, o ideal de masculinidade e de feminilidade, os conflitos familiares, os desafetos e as maldades que movem as relações interpessoais, a eterna luta entre o bem e o mal e, sobretudo, as possibilidades de

Copyright $\odot 2011$ by Revista Estudos Feministas. 
encontrarmos proteção e amor eterno ao final da história. Além dessas questões, há outras tantas acionadas pelos contos de fadas. "Nesse mundo de imaginação, não só nos libertamos das realidades enfadonhas da vida cotidiana, como nos entregamos aos prazeres catárticos de derrotar aqueles gigantes, madrastas, bichos-papões, ogros, monstros e trolls, estes também conhecidos como adultos".'

As histórias dos contos de fadas nos seduzem de várias formas, e talvez o fascínio pelas personagens da realeza se deva a elas, independente de não passarem da fantasia ou serem produtos da vida 'real'. Tal afirmação se comprovou com o fascínio e a curiosidade pelo casamento ${ }^{2}$ do príncipe William e da plebeia Kate Middleton, ocorrido recentemente na Inglaterra. Milhares de pessoas, em todo o mundo, assistiram à cerimônia, comentaram, especularam, sonharam (especialmente o público feminino) em também encontrar o príncipe encantado.

Por que, nos dias atuais, essas questões mobilizam tantas pessoas? Como podemos pensá-las a partir da categoria analítica e política de gênero? Quais as nossas representações de gênero na idealização de príncipes e princesas? Como construímos tais representações? Como essas representações são construídas por crianças?

Essas foram algumas questões levantadas em momentos de pesquisa-ação com um grupo de crianças de uma escola pública de Campo Grande, capital do Mato Grosso do Sul. As crianças e os pré-adolescentes, participantes da referida pesquisa com o apoio do CNPq, puderam descrever, por desenho, texto escrito e oralidade, o que consideram características de príncipe e princesa, bem como inventaram outros jeitos para a constituição identitária de cada uma dessas personagens.

Esses dados são aqui analisados sob a perspectiva teórica dos Estudos de Gênero, dos Estudos Culturais e de pressupostos da teoria foucaultiana.

Começaremos por um dos encontros da pesquisa com as crianças, embora a pesquisa mais ampla conte com dois eixos teórico-metodológicos interdependentes: a pesquisa bibliográfica de livros para a infância (publicados no Brasil dos anos 1930 até 2010) e a pesquisa-ação com crianças. Os produtos desta pesquisa constituem um catálogo digital com indicações das obras coletadas e analisadas na pesquisa e a produção coletiva de livro infantil e audiovisual ${ }^{3}$ com e para as crianças.

Os momentos de pesquisa-ação foram desenvolvidos em encontros semanais, no período matutino, com duração de quatro horas em cada uma das duas salas de aula do $5^{\circ}$ ano do ensino fundamental $\left(5^{\circ} \mathrm{A}\right.$ e $\left.5^{\circ} \mathrm{B}\right)$ de uma escola pública municipal da cidade de Campo Grande. As crianças (e alguns/as pré-adolescentes e adolescentes) têm idades médias entre 10 e 15 anos de idade (a maioria, entre 10 e 12 anos).

A pesquisa-ação ocorreu de agosto a dezembro de 2010. Antes do início, a proposta foi apresentada à equipe de direção da escola para autorização e, em seguida, a todo o corpo docente da escola, que atuava profissionalmente no turno de realização da pesquisa.

Outra reunião foi realizada com os familiares ${ }^{4}$ das crianças para serem informados sobre os objetivos e pressupostos metodológicos e poderem eventualmente expor suas

${ }^{1}$ Maria TATAR, 2004, p. 8.

2 Segundo alguns dados noticiados pela imprensa, estima-se que um milhão de pessoas estiveram nas ruas de Londres para prestigiar e celebrar o casamento real e que aproximadamente dois bilhões de pessoas pelo mundo acompanharam, em tempo real, a cerimônia (dados do jornal on-line O Globo).

3 No ano de 2010, produzimos um curta de animação com as crianças denominado Jéssica e Júnior no mundo das cores ( $3 \mathrm{~min}$.), em parceria com o instituto Animare (MG).

${ }^{4} \mathrm{Na}$ reunião de apresentação do projeto, compareceram oito responsáveis pelas crianças do $5^{\circ}$ ano $\mathrm{A}$ (perfazendo um total de $25 \%$ das crianças autorizadas posteriormente) e sete do $5^{\circ}$ ano $B(24 \%$ do total). Todas as demais pessoas autorizaram a participação das crianças; dessas, somente um menino não participou da pesquisa por motivos de saúde. 
objeções aos propósitos da pesquisa, além de autorizar a participação das crianças. Elas também foram informadas sobre o projeto e assinaram, junto com os adultos, o Termo de Consentimento Livre e Esclarecido. As crianças não autorizadas a participar dos encontros ficavam na escola com um trabalho individualizado, em companhia da professora ou do professor responsável pela sala.

Participaram dos encontros da pesquisa 48 crianças: ${ }^{5} 25$ estudantes do $5^{\circ}$ ano $A$ ( 16 meninas e nove meninos) e 23 do $5^{\circ}$ ano $B$ (seis meninas e 17 meninos). Da realização da atividade sobre princesas e príncipes, que será descrita a seguir, participaram 22 crianças do $5^{\circ} \mathrm{A}$ ( 13 meninas e nove meninos) e 20 do $5^{\circ} \mathrm{B}$ (cinco meninas e 15 meninos).

As atividades sugeridas para a apreensão e a discussão sobre as representações de gênero foram as seguintes: sugerimos que pensassem em uma princesa dos contos de fadas e também que se lembrassem das suas características físicas e comportamentais (onde moravam, qual era o nome, o que gostavam de fazer, quais seus desejos). Em seguida, receberam uma ficha para desenhar a princesa e escrever um texto contando sobre suas características pessoais. O mesmo ocorreu com a produção de texto e desenho sobre o príncipe.

Ao término, no grande grupo, as crianças falaram sobre as personagens escolhidas e as características principais. Construímos uma narrativa coletiva para observar quais seriam essas descrições.

Discutimos, em seguida, sobre essa construção cultural e social da figura feminina e da masculina. Propusemos que produzissem uma princesa e um príncipe de outro jeito. Outra ficha foi entregue para a realização dessa tarefa, reservando-se nela os espaços para o desenho e o texto sobre as personagens com características diferentes. Ao término da atividade, houve novas discussões. A atividade proposta em sequência foi a leitura coletiva de livros de recontos para a infância que traziam em suas narrativas personagens dos contos de fadas de forma pouco convencional. Essa foi a deixa para novas discussões e a produção de uma personagem feminina denominada de A princesa pantaneira.

Essas atividades destinavam-se a apreender e a discutir as representações de gênero que envolvem e dão vida às personagens dos contos clássicos de fadas que povoam o nosso imaginário e nossas representações coletivas da personagem feminina. Um segundo objetivo era desconstruir a figura clássica e idealizada da mulher dócil, submissa, romântica, casadoura, à espera da completude com o amor do príncipe.

\section{Princesas idealizadas: beleza, docilidade, meiguice}

A Cinderela é branca dos cabelos loiros que adora ratinho e cachorro. Ela gosta multo de fazer bolos e bombons, ainda mais para o Príncipe. O sonho de Cinderela era de se casar, e seu sonho se realizou, pois ela vai se casar no dia 20/11/ 2010 (texto de MENINA, 10 anos, $5^{\circ} \mathrm{A}$, grifos meus).

A princesa dos contos de fadas das narrativas das crianças, tanto das meninas quanto dos meninos, tem características físicas semelhantes: branca, loira, magra, alta, com cintura fina, cabelo comprido - liso ou levemente cacheado -; usa vestido comprido nas cores amarela ou rosa. Algumas meninas desenharam princesas com cabelos pretos, na altura do pescoço. O que se observou de destoante nas produções dos meninos em relação às das meninas é que elas incorporaram em seus discursos as imagens e as características socialmente aceitas e ensinadas sobre as princesas dos contos de fadas

${ }^{5}$ Quase $80 \%$ dos/as alunos/as matriculados/as nas duas séries foram autorizados/as a participar da pesquisa ( $78 \%$ do $5^{\circ}$ ano $A$ e $79 \%$ do $5^{\circ}$ ano $B$ ). 
clássicos. Já os meninos se ligaram a características diferentes das meninas, como princesas de cabelo curto, cabelo ruivo, cabelo desarrumado; princesa dentuça; princesa que usa bota, calça comprida e vestido na tonalidade azul.

As características pessoais e comportamentais das princesas também foram demarcadas nas narrativas. As comuns (de meninos e meninas) indicavam que a princesa seria feliz, vaidosa, linda, bonita, simpática, legal, alegre; que adoraria animais e gostaria de ter um príncipe encantado. Os meninos também afirmaram que as princesas têm amigos/ as; são sorridentes e gostam de boneca, vestido e calça. As meninas, por sua vez, falaram de inúmeras outras condutas desejáveis para a princesa, tais como asseio, doçura, discrição, delicadeza, inteligência, fofura, meiguice, amabilidade; e algumas competências, como gostar de cozinhar, ser prendada, ser divertida, gostar da cor rosa, não ser gulosa e ficar à espera do príncipe encantado.

As características físicas e comportamentais desejáveis da subjetividade das princesas são condizentes com o que se espera das condutas femininas ensinadas social e culturalmente. É interessante observar como essas adjetivações compõem as representações de gênero que demarcam a feminilidade hegemônica.

No início deste item, citamos um texto de uma menina com a descrição da princesa. Observamos algumas das características consideradas socialmente desejáveis para as mulheres: ser prendada na cozinha e ter o sonho da completude com o casamento heterossexual. Essas características, aliadas às outras descritas anteriormente, são atributos construídos culturalmente a respeito da constituição identitária feminina. São, na maioria das vezes, naturalizadas e consideradas normais e desejáveis para a vivência e conduta feminina. As características descritas das princesas dos contos de fadas clássicos remetem a corpos magros, esguios e ao cuidado com a vaidade. Outros elementos também aparecem para demarcar a feminilidade, entre eles (em alguns dos desenhos), a presença de flores e corações.

Os meninos também seguem o mesmo perfil de feminilidade presente nos discursos das meninas; no entanto, somente eles conseguem subverter essa imagem e incorporar outros aspectos, tais como adotar outras vestimentas e mudanças no visual, como cortes de cabelo mais ousados para as princesas.

Um dos meninos concebe uma princesa com outros elementos que não aqueles convencionais e hegemônicos a respeito da feminilidade. Nessa ilustração como em outra de outro menino, as princesas estão vestidas de azul (note-se que nenhum desenho das meninas apresenta roupa nessa cor), em nenhum dos desenhos elas apresentaram a princesa com outra roupa que não fossem os longos vestidos. Num dos desenhos as marcas estão presentes especialmente no coração estampado na blusa da princesa. Em outro desenho, o menino priorizou uma princesa de calça comprida e camisa na cor azul. O cabelo é curto e representa uma figura andrógina, portanto não indica o conformismo de um único modelo de ser mulher como o proposto pelo discurso, quase que uniforme, das meninas e de muitos meninos.

A afirmação de que a menina tem de usar o rosa e o menino o azul extrapola a questão ligada ao gosto pessoal por cores. Essa questão é eminentemente social, pois se aprende, desde muito cedo e no decorrer da vida, que essas cores identificam os meninos e as meninas. Essas cores produzem marcas identitárias, não permitindo pensar em outras formas de se fazer homem e de se fazer mulher. Ao contrário, demarcam a única forma legítima de ser masculino e de ser feminino. É interessante observar que esses discursos e convenções são ensinados às meninas desde muito cedo e, talvez por esse motivo, elas apresentem maior conformidade com as regras sociais, diferentemente do que ocorreu com a produção de alguns meninos. 
O conceito de gênero é fundamental para se entenderem as representações das crianças. Por gênero entende-se

a construção social feita sobre diferenças sexuais. Gênero refere-se, portanto, ao modo como as chamadas 'diferenças sexuais' são representadas ou valorizadas; refere-se àquilo que se diz ou se pensa sobre tais diferenças, no âmbito de uma dada sociedade, num determinado grupo, em determinado contexto.

As formas de constituir o masculino ou o feminino, como destaca Guacira Lopes Louro, são demarcadas e construídas socialmente. As cores rosa e azul tornaram-se marcas identitárias que definem um ideal de masculinidade e feminilidade, assim como as demais características físicas e comportamentais registradas pelas crianças na pesquisa-ação a respeito da constituição identitária da princesa e do príncipe.

As características desejáveis para as mulheres, destacadas nos textos - escritos e ilustrados - das crianças, mostram, na grande parte deles, um jeito único de ser feminino. Tais características apontam o que é ser feminino e, ao mesmo tempo, o que não é ser feminino, portanto masculino. Louro ${ }^{7}$ também nos alerta para a necessidade de construção de proposta da desconstrução das dicotomias, tão amplamente evidentes nas narrativas das crianças, como docilidade e agressividade, delicadeza e rudeza, meiguice e grosseria, entre outras tantas. Para a autora, uma das possibilidades de desconstruir as dicotomias é "problematizar a construção de cada pólo; demonstrar que cada um na verdade supõe e contém o outro; evidenciar que cada pólo não é uno, mas plural; mostrar que cada pólo é, internamente, fracturado e dividido". ${ }^{8}$

Foi esse, certamente, o desafio posto ao grupo de crianças e pré-adolescentes ao apresentarmos as características descritas das princesas. No entanto, houve, por parte de muitas delas, resistências em questionar os binarismos construídos socialmente. O que se conseguiu, em um primeiro momento, foi discutir a possibilidade de vivências de papéis diferenciados para meninos e meninas; no entanto, quando se propunham outras formas de ser princesa, como veremos adiante, pouco se conseguiu para desfazer essa demarcação tão rígida de gênero.

Para além das características físicas, comportamentais e identitárias das princesas, quais foram as personagens priorizadas nas produções das crianças?

As respostas podem ser divididas em duas perspectivas: uma delas, com as princesas dos contos de fadas clássicos; outras, inventadas ou denominadas de princesas. As princesas dos contos de fadas clássicos escolhidas pelos meninos e pelas meninas foram, em primeiro lugar, a Rapunzel; em segundo, a Branca de Neve; em terceiro, tivemos o empate entre Bela Adormecida e Bela (da história $A$ Bela e a Fera); em último, a Cinderela.

Outras princesas, inventadas ou corporificadas por personagens reais, foram a Princesa da Fada Azul; a Princesa Isabel; a Fiona (do filme de animação Shrek); a Pequena Sereia; a Princesa Barbie; a Formiga Faniquita; as princesas com nomes de meninas de algumas das alunas das séries investigadas: Lu, Mariana, Isabela, Ana Beatriz, Ricena, Mayara, Amanda, Maria Eduarda, Thayssa e Tina (também ganhei esse posto na concepção de algumas crianças).

As princesas dos contos clássicos, destacadas nas narrativas infantis, trazem características pessoais intrigantes para pensarmos sobre a construção identitária de gênero.

O conto de Rapunzel, dos Irmãos Grimm narra a história de uma menina trancada em uma torre, portanto segregada de toda a população, especialmente da masculina. $O$

${ }^{6}$ Guacira Lopes LOURO, 2000, p. 26.

7 LOURO, 2000.

${ }^{8}$ LOURO, 2000, p. 16.

${ }^{9}$ Todos os contos de fadas que descrevo neste artigo são descritos no texto de TATAR, 2004 
nome da princesa é oriundo de um tipo de hortaliça, rapunzel, que fora desejada por sua mãe quando estava grávida. Devido aos desejos da gravidez, pede ao marido que vá buscar no jardim da feiticeira a iguaria para comer em uma bela salada. A feiticeira, dona do jardim, no entanto, não gostou do roubo e, em um rompante de raiva, pediu para si a criança assim que nascesse. E assim ocorreu. Aos 12 anos, a feiticeira que criou Rapunzel como se fosse a sua mãe a trancou em uma torre sem escadas e porta. A menina tinha um longo cabelo loiro, trançado. Quando ouvia a voz da feiticeira, a menina jogava suas tranças para a sua mãe subir até o alto da torre. E isso ocorreu durante muitos anos, até que um dia um príncipe viu aquela cena e conseguiu subir a torre com a mesma estratégia usada pela feiticeira. Eles se apaixonaram. A feiticeira, ao saber da traição da filha, em um ataque de fúria, cortou o cabelo da menina e a levou para o deserto para viver uma vida miserável e infeliz. O castigo do príncipe foi ficar cego e vagar pela floresta chorando e lastimando a perda da amada. De tanto vagar, o príncipe chegou ao deserto em que Rapunzel estava. No fim da história, encontraram-se; ele recupera a visão e são felizes para sempre.

Branca de Neve também foi vítima da crueldade feminina. Ela nasceu branca como a neve e, logo após o seu nascimento, sua mãe veio a óbito. O rei casou-se novamente com uma mulher que não suportava a ideia de que alguém pudesse ser mais bonita do que ela. Ao perguntar ao espelho quem era a mais bela, ele a alertou sobre a beleza da menina. Por esse motivo, a rainha ordenou ao caçador a morte da enteada. Ele não lhe obedeceu e a deixou fugir floresta adentro. A menina encontrou a casa dos anões e por lá ficou algum tempo, até que a rainha a descobrisse e a induzisse a comer a maçã envenenada. A menina caiu em um sono profundo que somente foi despertado com o beijo do príncipe.

O enredo do sono quase eterno também aparece em outro conto, o da Bela Adormecida. Aqui a menina é amaldiçoada por uma feiticeira que fora banida da festa de comemoração do nascimento da menina. Ela lhe jogou uma praga, de que ao completar 15 anos espetaria o dedo num fuso e cairia morta. Para atenuar essa terrível praga, outra feiticeira, convidada para a festa, abrandou a morte transformando-a em sono profundo de cem anos. Isso ocorreu até que um príncipe conseguiu desbravar e abrir os caminhos até chegar à princesa, que foi acordada com um beijo seu.

A princesa Bela, do conto A Bela e a Fera, de Jeanne-Marie Leprince de Beaumont, também é uma moça bela e virtuosa, como as demais princesas já destacadas aqui. Obediente ao pai, para demonstrar toda a sua abnegação, oferece-se em sacrifício para salvar a vida dele. Vai morar na casa de um monstro, a Fera. Durante um tempo, ela consegue sair da casa da Fera; no entanto, tem um pesadelo e, ao acordar, em sobressalto, pensa: "Não é nem a beleza, nem a inteligência de um marido que fazem uma mulher feliz. É o caráter, a virtude, a bondade. A Fera tem todas essas boas qualidades". ${ }^{10}$ Imbuída dessa missão, ela volta ao convívio do monstro e ele se transforma em humano novamente. Casam-se e vivem felizes.

A última princesa citada pelas crianças é a Cinderela. Perrault narra a triste saga de uma menina que se inicia com a morte da mãe e o casamento do seu pai com a madrasta. A pobre menina suportava os maus-tratos da madrasta e de suas filhas sem se queixar. Aos poucos, ficou encarregada de todos os afazeres domésticos. Quando terminava a rotina árdua de trabalho, sentava-se em meio às cinzas, em um canto próximo à lareira. Por isso todos a chamavam de Gata Borralheira. Um belo dia, o príncipe convidou todas as moças do reino para um baile. Cinderela interessou-se em ir à festa, mesmo sem o incentivo da

${ }^{10}$ TATAR, 2004, p. 86.

596 Estudos Feministas, Florianópolis, 19(2): 591-603, maio-agosto/2011 
madrasta e muito menos das irmãs. Com a ajuda de uma fada madrinha e dos bichos da casa, ela vai ao baile e conhece o príncipe. Apaixonam-se à primeira vista. Com medo de o feitiço acabar e ter de revelar quem ela é, antes do badalar da meia-noite, a menina foge e, na fuga, perde seu sapatinho de cristal. É com ele que o príncipe irá fazer uma busca em todo o seu reino para encontrar a sua amada. No final, encontram-se, casam-se e vivem felizes para todo o sempre!

Todas as histórias das princesas selecionadas na pesquisa com as crianças são significativas para observar as representações de gênero.

O conceito de representação aqui adotado não é o de uma abstração mental ou de alguma interioridade psicológica, mas uma forma de atribuição de sentido. ${ }^{11}$ Tomaz Tadeu da Silva concebe o conceito como sistema de significados, atribuição de sentidos, traduzido por termos como inscrição, marca, traço, significação, face material, visível, palpável do conhecimento. ${ }^{12}$

As representações ganham sentidos e materialidade na linguagem. Esses sentidos são construídos socialmente e compartilhados pelos sujeitos. Quando observamos as características das princesas dos contos de fadas destacadas pelas crianças e pelos/as pré-adolescentes da pesquisa-ação, podemos perceber quais os significados compartilhados por elas e pela cultura a respeito do que se espera da identidade de gênero das mulheres e dos homens.

Ao procurar entender as representações de gênero das crianças, tomando como referência as características das princesas dos contos de fadas referidos, conferimos o que elas esperam da conduta dessa personagem. Elas devem ser delicadas, abnegadas, submissas, pacientes, cordatas, obedientes. Todas são brancas, magras e jovens. Desse grupo de princesas, a única que tenta resistir às normas impostas seria a Rapunzel, que, apesar de enclausurada, segregada, isolada, encontra-se com o príncipe e tem uma relação amorosa às escondidas. Essas questões não são tão evidentes em algumas versões desse conto de fadas; no entanto, segundo Tatar, ${ }^{13}$ a sugestão de que os encontros diários com o príncipe haviam conduzido à gravidez foi, segundo a autora, considerada imprópria para crianças e, por isso, o conto ganha outras narrativas.

Não se deseja aqui fazer uma análise psicanalítica ${ }^{14}$ dos contos de fadas. Não se pretende insinuar que essa não seja uma perspectiva apropriada para buscar entender as questões inconscientes na construção da subjetividade masculina e feminina. No presente estudo nosso objetivo é verificar como as características femininas consideradas ideais estão tão fortemente presentes nos discursos das crianças, com isso produzindo subjetividades. Parece que essas questões são mais evidentes nas meninas do que nos meninos. Talvez porque os contos de fadas tenham se tornado ao longo dos anos leitura indicada para o público feminino. Possivelmente por esse motivo, além das próprias constituições identitárias vividas no cotidiano, não tenham conseguido resistir às normatizações de gênero.

Os meninos, na pesquisa, conceberam outros tipos de feminilidade. É importante frisar, contudo, que as meninas, tal como os meninos, não são seres passivos diante das normas de gênero. Apesar da "conformidade" apresentada, em algumas narrativas se

\footnotetext{
${ }^{11}$ Tomaz Tadeu da SILVA, 2003.

12 Sobre este tema, sugiro a leitura dos seguintes livros: Bruno BETTELHEIM, 1986; e Diana Lichtenstein CORSO e Mário CORSO, 2006.

13 TATAR, 2004.

${ }^{14}$ Sobre este tema, sugiro a leitura dos seguintes livros: Bruno BETTELHEIM, 1986; e Diana Lichtenstein CORSO e Mário CORSO, 2006.
} 
esboçam algumas formas de resistência que rompem as fronteiras convencionais de gênero. Abordaremos mais especificamente essas questões na descrição do príncipe.

\section{Príncipes idealizados: coragem, elegância, romantismo}

Os príncipes rememorados pelas crianças na pesquisa podem ser classificados em três agrupamentos: os príncipes dos contos de fadas clássicos; os príncipes da princesa Barbie; e outros 'reais' e inventados.

Os príncipes dos contos de fadas clássicos citados foram: em primeiro lugar, a Fera, do conto A Bela e a Fera; em segundo, empatados, o Príncipe da Bela Adormecida, o Príncipe da Branca de Neve e o Príncipe da Cinderela; em último, o Príncipe da Rapunzel.

É curioso observar que os príncipes dos contos de fadas escolhidos não têm nomes próprios: são simplesmente príncipes das princesas. Para serem reconhecidos, necessitam dizer a qual princesa 'pertencem'. Mesmo a Fera, do conto A Bela e a Fera, após a transformação de monstro em príncipe, não chega a ter um nome próprio. Duas crianças, incomodadas com essa não identificação dos príncipes, atribuíram nomes para designar o Príncipe da Cinderela. Os nomes escolhidos foram príncipe Charles e príncipe Lucas.

Os príncipes da Barbie foram citados exclusivamente pelas meninas. Eles são personagens de filmes ${ }^{15}$ cuja protagonista é a boneca. Também nem sempre esse príncipe tem nome. Algumas o chamaram de Ken; outras, de Príncipe da Barbie do filme tal, referindose ao desempenho do príncipe a partir do roteiro da história.

O que é importante observar é que, apesar de a protagonista ser a menina/mulher nos contos de fadas clássicos, ou nos filmes interpretados pela Barbie, os príncipes ocupam um duplo lugar, ora como coadjuvantes das tramas (sem ao menos terem um nome próprio), ora no papel principal, especialmente no final das histórias, transformando-se naqueles que virão salvar a princesa e desposá-la, completando-a e atribuindo um final feliz à história.

O ideal de amor romântico é constantemente reforçado nas histórias. Essa questão foi analisada por Suyan Maria Ferreira Pires, quando pesquisou o amor romântico em livros infantis. A autora assegura que essa construção envolve:

quem ama procura um par, pois em todo amor há pelo menos dois seres envolvidos e, quando correspondido, pode ser estabelecida uma relação. A partir de então nota-se uma tênue fronteira entre o sentimento e a forma de gerenciá-lo, que comumente é implacável. Uma vez constituída essa relação, pode-se perceber o sentimento de amor dos apaixonados sendo vivido, abundantemente, com o desenrolar das situações. ${ }^{16}$

A construção e a legitimação do amor romântico ocorrem nos contos de fadas e nas vivências de completude, especialmente da princesa. Essa forma de se relacionar, contudo, é construída social e culturalmente. Jurandir Freire Costa analisa historicamente a construção desse sentimento:

O amor é uma crença emocional e, como toda crença pode ser mantida, alterada, dispensada, trocada, melhorada, piorada ou abolida. $O$ amor foi inventado como o fogo, a roda, o casamento, a medicina, o fabrico do pão, a arte erótica chinesa, o computador, o cuidado com o próximo, as heresias, a democracia, o nazismo, os

\footnotetext{
${ }^{15}$ No site da Barbie é possível observar a grande quantidade de filmes protagonizados pela boneca desempenhando o papel de princesa, entre eles: Vestindo uma princesa; Barbie, magia de Aladus; Barbie e as três Mosqueteiras; Barbie em Castelo de Diamantes; Barbie em a Princesa da llha; Barbie - A princesa e a plebeia; Barbie e o casamento de Rapunzel (BARBIE, 201 1). Está para ser lançado no segundo semestre de 2011 o filme Barbie em Escola de Princesas.

${ }^{16}$ Suyan Maria Ferreira PIRES, 2009, p. 84.
} 
deuses e as diversas imagens do universo. Nenhum de seus constituintes afetivos, cognitivos ou conativos é fixo por natureza.

A representação do amor romântico é constantemente narrada pelas crianças na pesquisa-ação. A figura do coração está presente especialmente nos desenhos das meninas, completando o quadro de romantismo esperado para a vivência das personagens. Entre as características dos príncipes citadas por elas, algumas são consideradas próprias da virilidade, de gentileza ou do romantismo. As da primeira categoria descrevem o príncipe como alguém forte, charmoso, batalhador, destemido, desbravador, corajoso, inteligente, alegre, que gosta da família e dos animais. Ao mesmo tempo, esperase que o príncipe seja delicado, romântico, gentil, carinhoso, bom, justo, com bons modos, que não seja guloso e preguiçoso. Uma das meninas desenhou um príncipe bailarino, em contraposição à ideia hegemônica de masculinidade.

Para os meninos, os príncipes gostam de jogar bola e procuram o equilíbrio em ser vaidosos. Talvez a afirmação de que o príncipe pudesse ser muito vaidoso poderia macular a imagem de másculo, construída como ideal de masculinidade.

As características comportamentais comuns ao príncipe dos meninos e das meninas são ser feliz, lindo, guerreiro, 'gostoso', legal; ser apaixonado pela princesa e querer casarse com ela. As características físicas salientadas pelos dois gêneros descrevem um príncipe branco, jovem, alto, loiro ou moreno, cabelo curto e que usa calça comprida, camisa e coroa.

As meninas reforçam a característica de romantismo, desenhando os príncipes com flores nas mãos. Como já destacado, as narrativas das meninas instigam a construção de um novo tipo de masculinidade. Como vemos nos textos produzidos:

O príncipe Carlos tem cabelo preto e olhos castanhos. Ele é um menino muito bom, tem 21 anos e é um menino muito lindo e delicado (MENINA, 12 anos, $5^{\circ} \mathrm{A}$ ).

O príncipe Suexy é lindo, charmoso, bonito, não joga nada no chão. É bem delicado, não é guloso e não é preguiçoso (MENINA, 10 anos, $5^{\circ} \mathrm{A}$ ).

Lucas é branco, tem cabelo preto e gosta de trabalhar com o seu pai. Ele ficou muito feliz com o seu casamento. Ele adora muito cachorro e bolo que a Cinderela faz (MENINA, 10 anos, $5^{\circ} \mathrm{A}$ ).

Os príncipes citados pelas meninas desempenham um tipo de masculinidade que povoa o imaginário feminino. Ele é sensível, cortês, doce, porém com a medida certa de virilidade para poder salvar a princesa em perigo.

Os desenhos das meninas tenderam a ser mais tradicionais, reportando-se às imagens dos príncipes dos contos de fadas, diferentemente do que expressaram no texto escrito. Duas meninas destoaram dessa representação de masculinidade dos príncipes e os desenharam como seres frágeis, com longos cabelos compridos e sedosos e um deles como bailarino. Um dos meninos também seguiu essa mesma representação e desenhou o príncipe chorando, possivelmente por amor.

Os meninos tendem a se identificar com o príncipe dando-lhe seus próprios nomes (Tom, Gabriel, Carlos, Bruno, Luís, Jeferson, Geovane, Lucas, Léo, Marcos, Bruno e Daniel, que foi um dos colaboradores na pesquisa); também o vestem com roupas usadas e preferidas pela juventude: boné, tênis, camiseta, bermuda. Em sua maioria, são másculos, musculosos, altos e esguios.

É possível ver algumas ousadias introduzidas na figura clássica de masculinidade hegemônica, em especial, atribuir características da adolescência na constituição do

17 Jurandir Freire COSTA, 1998, p. 12. 
príncipe. Os meninos ousam mais, vestindo-os com roupas cor-de-rosa ou com indumentárias típicas da adolescência. Eles também se identificam com os príncipes, dando-lhes seus próprios nomes ou os de colegas de sala de aula. Outro dado presente nos desenhos dos meninos e inexistente nos das meninas é o desenho de armas, como espada, próximo ao príncipe.

Assim como ocorre com as princesas, todos os príncipes são brancos. Somente um menino desenhou um príncipe negro e assim o descreveu: "Artur, ele é feio pra caramba é negro, vagabundo" (MENINO, 10 anos, $5^{\circ} \mathrm{B}$ ). No texto do menino, é possível observar como se estabelece a norma; tudo o que foge dela é considerado inadequado, feio, desprezível. Louro analisa essa questão ao ressaltar:

na nossa sociedade, a norma que se estabelece, historicamente, remete ao homem branco, heterossexual, de classe média urbana e cristão e essa passa a ser a referência que não precisa mais ser nomeada. Serão os 'outros' sujeitos sociais que se tornarão 'marcados', que se definirão e serão denominados a partir dessa referência. ${ }^{18}$

No texto do menino, fica evidente que a norma da branquidade exclui seres de outras identidades étnicas, como o negro, considerado feio e vagabundo. O mesmo ocorre com outras diferenças como a homossexualidade. Essa orientação sexual nem sequer foi citada pelas crianças, no entanto os próprios contos de fadas são instrumentos de artefatos culturais que visam educar para a heteronormatividade.

Débora Britzman utiliza-se do conceito de Michel Warner e destaca que a heteronormatividade caracteriza-se pela "obsessão com a sexualidade normalizante, através de discursos que descrevem a situação homossexual como desviante". ${ }^{19}$ Os discursos que privilegiam a heterossexualidade, como a única possibilidade de constituição identitária sexual, constituem-se em um conjunto de normas, mecanismos e dispositivos que fazem parte das várias pedagogias da sexualidade e de gênero presentes socialmente e que capturam as crianças desde muito cedo. Um dos exemplos significativos são os contos de fadas, que reforçam a matriz heterossexual com o reforço da relação amorosa e do enlace final, com o casamento, e da demarcação do destino imutável do 'e foram felizes para o resto de suas vidas'! Essas questões tornaram-se presentes e povoaram as representações das crianças, sujeitos da pesquisa-ação.

Esse tipo de análise é importante por mostrar como e quanto alguns conceitos são legitimados, constituindo a única verdade. Isso se deve ao investimento das relações de poder que, ocorrendo em rede, estabelecem algo como o 'correto' e, portanto, afetam e capturam os sujeitos, constituindo subjetividades.

\section{Príncipes ou princesas de outros jeitos ou a construção e reafirmação do mesmo?}

Em continuidade às discussões propiciadas pelos momentos da pesquisa com as crianças, pedimos que propusessem uma princesa e um príncipe de outro jeito. Em alguns trabalhos, as princesas ganharam novas características: relaxada, esperta, forte, inteligente, brincalhona, roqueira, fanqueira, corajosa. No entanto, persistiram para a feminilidade os mesmos atributos desejáveis numa princesa idealizada, especialmente nos textos das meninas. As princesas de outros jeitos continuam vaidosas, à espera do príncipe, chiques, bonitas, ricas, superstar; gostam de se maquiar; andam na moda; têm longos cabelos. $O$

${ }^{18}$ LOURO, 2000, p. 66

19 Deborah BRITZMAN, 1996, p. 79 
ideal de juventude, branquidade e magreza persiste nessa nova construção solicitada para as crianças.

Os meninos conseguem ousar e criam novas possibilidades. Constroem outras formas de subjetividade: a princesa deficiente física, 'meio negra'(sic!), que fuma cigarro e toma pinga, feia, cheia de verruga. Os meninos também desenharam seres inanimados para representar a princesa de outro(s) jeito(s). Um deles criou uma princesa com mãos de onde sai fogo ou com olhos que amaldiçoam as pessoas e com pernas como redemoinhos.

Na maioria das narrativas, as princesas ganharam contornos contemporâneos e, com isso, seus corpos ficaram mais à mostra, demonstrando mais sensualidade. As princesas estão vestidas de tops, biquínis e saias curtas e justas.

A 'nova' princesa, ou a princesa de outro jeito, possui os atributos desejados da feminilidade idealizada, mas agora elas devem ser também sexy e sensuais. O processo da erotização das meninas já é objeto de estudo. Desde muito tempo ele vem sendo acionado para produzir meninas sensuais, desejantes e desejáveis. Jane Felipe ${ }^{20}$ alertanos para o processo de pedofilização como processo social. Para ela, o corpo erotizado das meninas é constantemente colocado em discurso por meio de diferentes artefatos culturais. Esses discursos são conflitantes e ambivalentes, pois, ao mesmo tempo que produzem um encantamento do adulto pela infância, especialmente pelo público masculino, convivem com outros que pretendem proteger os direitos de crianças e adolescentes, coibindo o alto índice de violência sexual, por exemplo.

Os outros jeitos para os príncipes também mantiveram os atributos da idealização. Alguns poucos os mostram 'cheinho' (indicando ser gordo), estiloso, vaidoso. Alguns foram descritos como maloqueiros, roqueiros, doidos, surfistas, dorminhocos. São os meninos, todavia, que criam novas configurações fantasiosas: príncipe com quatro braços, príncipe com cabeça de abóbora e mãos de serra elétrica e tesoura, príncipe esqueleto, príncipe meio humano e meio bicho.

\section{Considerações finais}

Como vimos neste artigo, a partir dos dados coletados em pesquisa-ação com crianças, as representações de gênero que construíram estão fortemente presentes e reforçadas na sociedade. Os discursos de ideal de feminilidade parecem afetar mais as meninas justamente pelas várias pedagogias de gênero que interagem desde que nascem. Esse processo também ocorre com os meninos; no entanto, nesta pesquisa, parece que eles conseguem subverter o padrão de convencional e resistir a alguns de seus dispositivos. Prestando atenção à grande maioria, o que se observa é que as representações de gênero estão fortemente carregadas com o que se espera convencional e historicamente das meninas: delicadeza, submissão, doçura, além de sensualidade e ousadia. Dos meninos espera-se: valentia, coragem, fortaleza, paixão. São eles que desbravam o espaço público, em detrimento das meninas, às quais ainda se reservam os espaços privados e domésticos.

Como instigar a construção de novas formas de ser menino e menina? Como as crianças e os/as adolescentes podem questionar os vários discursos que prevalecem nas mais diversas pedagogias culturais?

Visando propiciar a discussão sobre essas novas possibilidades de constituição de feminilidade e masculinidade, quatro livros para a infância com recontos de fadas foram lidos e analisados pelas crianças. São eles: A princesa Sabichona e Príncipe Cinderelo, de Babette Cole; O sapo que virou príncipe: continuação, de Jon Scieszka; e Até as princesas

${ }^{20}$ Jane FELIPE, 2006. 
soltam pum, de llan Brenman. Os dois primeiros livros se propõem a desconstruir as imagens dicotômicas e binárias do masculino e do feminino. A princesa Sabichona, por exemplo, prefere ficar sozinha a casar. O príncipe Cinderelo é frágil e ocupa a posição desempenhada pela Cinderela no conto clássico. O sapo que virou príncipe analisa a sua própria identidade de humano e questiona a sua relação com a princesa; por fim, tem-se a desconstrução da imagem idealizada da princesa que solta 'pum'.

O objetivo da discussão dos conteúdos e de personagens privilegiados por esses livros foi propiciar momentos de discussão e diálogo sobre as construções identitárias de meninos e meninas. Que novas possibilidades de ser podem ser gestadas e vividas? Por que as normas de gênero ganharam legitimidade? Como as relações de poder estão presentes na construção da identidade e da diferença? Como questionar os binarismos de gênero? Essas foram as questões apresentadas às crianças, tentando, evidentemente, provocar discussões a partir de exemplos cotidianos de suas vivências.

Como atividade final, passamos a construir coletivamente uma personagem denominada de $A$ princesa pantaneira. Ela vive no pantanal sul-mato-grossense e é totalmente diferente da imagem idealizada da princesa convencional que povoa as representações das crianças. Essa princesa será a personagem principal do livro para a infância que escrevemos coletivamente entre crianças e adultos da pesquisa.

O que se deve observar, para efeito de síntese final, é que as crianças estão imersas nas representações hegemônicas de feminilidade e masculinidade. Outras possibilidades podem ser produzidas à medida que se promovam debates, diálogos e problematizações a respeito do que parece representar a única verdade. Pretende-se, com isso, desconstruir dicotomias tão fortemente legitimadas nos discursos e nos processos de subjetivação de meninas e meninos.

\section{Referências bibliográficas}

BARBIE. Disponível em: <http://br.barbie.com/> Acesso em: 19 maio 2011.

BETTELHEIM, Bruno. A psicanálise dos contos de fada. 6. ed. Rio de Janeiro: Paz e Terra, 1986. BRENMAN, llan. Até as princesas soltam pum. 3. reimpressão. São Paulo: Brinque-Book, 2008.

BRITZMAN, Deborah. "O que é esta coisa chamada amor: identidade homossexual, educação e currículo". Educação \& Realidade, Porto Alegre, n. 21, p. 71-96, jan./jun. 1996.

COLE, Babette. A princesa Sabichona. São Paulo: Martins Fontes, 1998. Príncipe Cinderelo. São Paulo: Martins Fontes, 2000.

CORSO, Diana Lichtenstein; CORSO, Mário. Fadas no divã. Porto Alegre: Artmed, 2006.

COSTA, Jurandir Freire. Sem fraudes nem favor: estudos sobre o amor romântico. Rio de Janeiro: Rocco, 1998.

FELIPE, Jane. "Quem é mesmo o pedófilo?". Cadernos Pagu, Campinas, p. 201-223, 2006.

LOURO, Guacira Lopes. Currículo, gênero e sexualidade. Lisboa: Porto Editora, 2000.

O GLOBO. Disponível em: <http://oglobo.globo.com>. Acesso em: 19 maio 2011.

PIRES, Suyan Maria Ferreira. "Amor romântico na literatura infantil: uma questão de gênero". Educar, Curitiba, n. 35, p. 81-94, 2009.

SCIESZKA, Jon. O sapo que virou príncipe: continuação. São Paulo: Companhia das Letrinhas, 1998.

SILVA, Tomaz Tadeu da. "A produção social da identidade e da diferença". In: (Org.). Identidade e diferença. 2. ed. Petrópolis, RJ: Vozes, 2003. p. 73-102.

TATAR, Maria. Contos de fadas: edição comentada e ilustrada. Rio de Janeiro: Jorge Zahar, 2004. 
[Recebido em 15 de março de 2011 e aceito para publicação em 10 de maio de 2011]

Once Upon a Time, There Were a Princess and a Prince...: Gender Representations in Children's Narratives

Abstract: Gender representations in fairy tales were the focus of an action research with public school children in Campo Grande, Brazil. This paper is part of a larger study, funded by CNPq, which involves two moments: bibliographical reasearch for the selectio and analysis of children's books dealing with sexuality, gender and diversity, and the action research with children and adolescents. In this second moment, the emphasis is on the discussion of narrative and pictorial texts produced by the children and on the reading of the books selected. This paper presents some of the data collected in the second moment of the project. We seek to understand how they construct gender representations based on the physical and behavioral descriptions of princesses and princes in classical fairy tales. We have observed that the representations are connected to socially hegemonic ideals of masculinity and femininity. Some resistance appears in the textual productions of the boys. The girls seem to conform to gender norms as ideal and desirable for their personal identities.

Key Words: Gender Representations; Research with Infants; Gender. 